\title{
Thomas Jones' Neapolitan Kitchen: The Material Cultures of Food on the Grand Tour
}

\author{
Melissa Calaresu \\ Gonville and Caius College, Cambridge \\ mtc12@cam.ac.uk
}

\begin{abstract}
The Welsh painter, Thomas Jones, recorded in minute detail the prices, origin, and types of food and services for each day of his family's stay in Naples from their arrival from Rome in 1780 to their departure for England in 1783 . His "Italian account book" has not been studied before in any depth, except in relation to his activities as an artist. However, this "time-capsule" of a Grand Tour household provides an extraordinarily vivid entry into the material world of urban provisioning in one of the largest cities in eighteenth-century Europe, by linking the economy of the street to wider networks of provisioning from outside of the city. It also provides a better understanding of the extent of acculturation of British residents in Italy. Space, time, and the interconnectedness between the home and the street are central themes in this material culture analysis of food on the Grand Tour.
\end{abstract}

\section{Keywords}

Grand Tour - material culture - history of food - kitchens - Naples - urban history

\section{Introduction}

The Welsh artist Thomas Jones (1742-1803) began painting a view of the kitchen in his family's apartment across from the Dogana del Sale, or Salt Custom House, in Naples on May 17, 1781: "The Subject was prosecuted and finished con Amore - when I tired of other things, I painted on my Kitchen Scene by way of Relaxation \& Amusement, and I still keep this picture by me as a pleasant 
reminder of Times past." Jones wrote this entry in his "Memoirs" from his farmhouse in Wales in late 1798, exactly fifteen years after his return from Naples. The painting no longer survives but its execution and the emotional comfort which it clearly provided years later intimates the important role of his Neapolitan kitchen in the life of Thomas Jones and his family. In fact, as his "Memoirs" attest, kitchens seemed to have been a particular preoccupation for Jones throughout his time in Italy from 1778 until 1783 . Yet, kitchens and their contents-often left out of inventories and notoriously difficult to reconstruct-have only recently become a topic of interest for historians. ${ }^{2}$ Although the objects depicted in Jones' kitchen scene painting are not known, he recorded every purchase he made — most of it food—during his three years in Naples from May 1780 to August 1783 in a vellum-covered book of accounts now in a County Council archive in Wales. ${ }^{3}$ His "Italian Account Book" provides an extraordinary record of the day-to-day material workings of an urban kitchen in one of the largest cities in Europe. ${ }^{4}$ The documentary value of his accounts is undeniable - from pots, pans, and kitchen implements which were purchased and discarded to an array of mostly fresh fruit and vegetables, cuts of meat, and kinds of fish and seafood which were consumed by his family. A material culture approach to his accounts brings to life the urban context in which Jones and his family lived and ate-it resonates with the voices of the street-sellers, holding bunches of the new season's fresh peas in their hands, it evokes the time taken to have a coffee in a café in the morning or to buy fish for dinner in the evening, and links the networks radiating from the city to its hinterland of market gardens and dairy producers. By focusing on time and space, Jones' accounts extend our knowledge of the materialities of food in an early modern context from the table to the kitchen and from the kitchen to the city.

1 The entry for 17 May 1781 begins: "I began a view of my Kitchen on a 4 Palm Cloth, this being the first attempt at Still Life." Thomas Jones, "Memoirs of Thomas Jones: Penkerrig Radnorshire, 1803," The Walpole Society 32 (1946-1948): 103. References will also be made to the corresponding folio in the original manuscript, "Memoirs of Thomas Jones, Pencerrig," National Library of Wales, MS 23812D, f. 204.

2 Most recently, Deborah Krohn, Food and Knowledge in Renaissance Italy: Bartolomeo Scappi's Paper Kitchens (London, 2015) and Sara Pennell, The Birth of the English Kitchen, 1600-1850 (London, 2016).

3 “Thomas Jones' Italian Account Book," Powys County Archives, R/SOC/4/7. I am grateful to Roz Williamson, Catherine Richards, and Julie Ryan of Powys County Council for kindly allowing me access to the digitised version of the manuscript.

4 Jones and his family were in this apartment from May 1780 until June 1782 after which they moved to a third-floor apartment in a house on the road going up to Capodimonte ("Memoirs of Thomas Jones," 112; ff. 232-234). The focus of this essay is primarily on the kitchen in their first apartment. 
They also contribute to understanding better the processes of acculturation of Grand Tourists who became longer term residents in Italy.

\section{Thomas Jones' “Italian Account Book”}

Thomas Jones spent seven years in Italy, the last three in Naples, unsuccessfully pursuing a career as a landscape painter. The length of his stay in the city distinguishes Jones from other Grand Tourists who normally would stay a few weeks or perhaps a season before moving on to another city. ${ }^{5}$ His "Italian Account book" was "discovered" when he began to enjoy favor with British art historians and the British public in the 1950s-more than 150 years after he died-after his "Memoirs" were published and a number of his paintings came on to the art market. ${ }^{6}$ His posthumous fortune stemmed almost entirely from an admiration for his highly detailed oil paintings on paper of the built environment in Naples, rather than his landscapes on canvas. It was, in fact, this "due attention to the Detail — that is to say, minute finishing," admired by some of his contemporaries such as Jacob Philipp Hackert, that also distinguishes Jones' "Account Book."7 It has been used by art historians to aid their study of the art materials that Jones bought and used in Naples-paint, paper, canvas, brushes - and his working processes as an artist. ${ }^{8}$ Other than for the drawings it contains-sometimes serving as preparations for larger studies-the "Account Book" has been of little additional interest to art historians and of no interest to historians of Naples. Yet, three quarters of the Book-fifty-nine of the eighty folio pages — are taken up by his accounts of what he bought over

5 See Melissa Calaresu, "Life and Death in Naples: Thomas Jones and Urban Experience in the Grand Tour (Explorer)," in A World Made by Travel: The Digital Grand Tour, Part 4: Scholars' Essays: Digitizing the Grand Tour, eds. Giovanna Ceserani and Rachel Midura (Stanford, 2020) https://www.worldmadebytravel.org/scholars-essays/calaresu-life-and-death.

6 Anne Sumner, "Who was Thomas Jones? The Life, Death, and Posthumous Reputation of Thomas Jones of Pencerrig," in Thomas Jones (1742-1803): An Artist Rediscovered, eds. Anne Sumner and Greg Smith (New Haven, 2003), 10.

7 "Memoirs of Thomas Jones," 117; f. 350 However, this "exactness of detail" came off as "very cold—like china" to one of his contemporaries. "Introduction" to "Memoirs of Thomas Jones," iv.

8 The Book appears as "Account Book with Notes and Sketches, Showing 'A Bridge near Florence," in Thomas Jones, eds. Sumner and Smith, Cat. entry 73, 182. On his purchase of paint supplies, see Kate Lowry, "Thomas Jones: A technical study of his oil paintings," and Peter Bower, "Careful and considered choice: Thomas Jones's use of paper," in Thomas Jones, eds. Sumner and Smith, 92 and 101-102, respectively. 
three years from his arrival in Naples from Rome on May 20, 1780 to his departure from the city by boat to England on August 21, 1783..$^{9}$ Dated and divided into entries in single columns, and from the sixth page in double columns, Jones lists all of the items and services bought individually or together, with amounts, weights, and prices, including a final total sum paid for the day. The entries appear in English, Italian and occasionally Neapolitan.

As noted, the information relating to food provided by Jones in his "Italian Account Book" is unusually rich and detailed, and even overwhelming. ${ }^{10}$ Adam Smyth has argued that financial accounts from the early modern period cannot simply be read as a "depository of historical facts" in isolation. He recognizes their important autobiographical potential, if they are read alongside other kinds of record and "life writing" and if we understand the process by which they were created and also used to create other documents. ${ }^{11}$ This is certainly possible in relation to the two manuscripts by Jones, one of which was openly autobiographical in intent; in his "Memoirs," he writes that, "I have related Occurrences, which though Ordinary, were matter of facts."12 His descriptions of special dinners in his "Memoirs" often correspond with specific costs noted in his "Account Book." ${ }^{3}$ For example, a Sunday lunch with a Danish captain, an Irish Cadet called Mr. Flemming "who often did me the honor of dining and Supping at my house," and others including the artist William Pars corresponds with the buying of an unusually large amount and variety of beef, mutton, and goat meat (vaccina, castrato, capretto) as well as fruit, lemons, salad (insalata), pasta (fedelini), cheese (cascio d'olanda), bread (al fornaro), and liquor (acquavita) on the day before and the day of the lunch. ${ }^{14}$ Smyth rightly suggests that notwithstanding the appearance of objectivity, financial

This period is covered in "Thomas Jones' Italian Account Book," Powys County Archives, $\mathrm{R} / \mathrm{SOC} / 4 / 7$, from ff. $2 \mathrm{r}$ to 6 ov. Other material in the Account Book which can safely be dated to his time in Naples includes a conversion chart for Neapolitan currency (f. 69v) and a list of standard weights and measures in Naples (f. 7ov). All references will appear as "Italian Account Book."

10 Some of my analysis will be based on a database of Jones' entries created with the support of the Cambridge Humanities Research Grant Scheme (2018) and the essential input and expertise of Irene Galandra and Janine Maegraith. The database will be a key source for a broader study of Jones' time in Naples which I am currently writing.

Smyth uses the example of Samuel Pepys who partly structured his diary from financial accounts; Adam Smyth, Autobiography in Early Modern England (Cambridge, 2010), 58-59. "Appendix," in "Memoirs," 140; f. 432.

13 It is not clear whether Jones used the accounts to structure his Memoirs since he mentions the existence of a "Memoranda of a Diary" when writing them; "Appendix," in "Memoirs," 140; f. 432.

"Memoirs," 8 July 1781, 106; f. 212, and "Italian Account Book," 7 and 8 July 1781, f. 25 r. 
accounts can also be "rhetorical, artful, partial."15 Despite the semblance of completeness of Jones' accounts, a number of unknown - and possibly more ordinary-items appear under the category of general expenses (spese) or the equivalent of etc. (et et et). There are also significant absences in both the "Memoirs" and "Account Book," such as the birth dates of Jones' two daughters whose arrival and presence are clear by payments made to a wet nurse throughout his time in Naples. ${ }^{16}$ There are only rare mentions of his Danish wife, Maria Moncke, who appears first as his housekeeper in his "Memoirs" but appears simply as "M" in the "Account Book" (arguably, she is also present in a recipe for shoe polish described as "Danish"). ${ }^{17}$ There are also disconnections between the two manuscripts. For example, while specific holidays are never mentioned in his "Memoirs," it is clear from the accounts that Jones's household took feasting seriously; sweetmeats (confetti), oranges (aranci), and nutmeg (noce di Moscato) were bought for New Year's Eve in 1780 and a turkey (un gallinaccio) for Christmas in $1782 .{ }^{18}$ Finally, while Jones recorded the purchases, we do not know who did the shopping, nor the extent to which his Danish wife, or even the household's Neapolitan servants, contributed to food choices for the household. ${ }^{19}$ Identifying these absences and disconnections related to food, alongside the wealth and detail of information that the two manuscripts provide, can help piece together the physical and emotional rhythms of the Jones family's life, but the accounts can also tell a broader story about the urban kitchen - the space where this food was carried, prepared, and cooked-and its relationship with the city.

15 Smyth, Autobiography in Early Modern England, 61.

16 Jones starts off with a single small payment to a balia from 23 September 1780 and later monthly payments to a nutrice from 12 October 1780; "Italian Account Book," f. 11 r and f. 11v. In his "Memoirs," he first mentions his nurse, Anastasia, on 3 May 1782 and later as "the good Anastasia, my Childrens Nurse" on 29 April 1783; "Memoirs," 112 and 122; f. 226 and f. 364 .

17 Memoirs," 89; ff. 158-9. The first payment "to M." was made on 4 November 1780; "Italian Account Book," f. 12v. The recipe appears on f. $70 \mathrm{v}$. There is a family portrait from 1797 by Francesco Renaldi (National Gallery of Wales, NMW A 92).

18 "Italian Account Book," 30 and $3_{1}$ December 178o, f. 15v. On Christmas Eve of that year, he bought pig's feet (piedi di porco), a food traditionally eaten during the Christmas season (f. 15r). On 24 December 1782, he not only bought a turkey but also 2 chickens, beef, sausages, fruit, salad, half a barrel of wine, and a candlestick (f. 5 or). Turkeys were often bought as gifts to religious houses during the Christmas season; Romano calculated a higher price for a gallodinia, another term for a turkey, at 75 grani in 1782; Ruggiero Romano, Prezzi, salari, e servizi a Napoli nel secolo XVII (1734-1806) (Milan, 1965), 83.

19 On who bought the goods for households in Renaissance Italy, including elite men, and how they were conveyed home, see Evelyn Welch, Shopping in the Renaissance: Consumer Cultures in Italy, 1400-160o (New Haven, 2005), 212-243. 


\section{The Urban Kitchen}

Thomas Jones' first kitchen in Naples makes an early appearance in his "Memoirs" in an unusually detailed description of the apartment that he had rented for his family, on the second-floor of a newly-built palace in a square close to the port. He writes:

The ground Appartments were all appropriated to Warehouses - the first and second floors were each intended for two Small families, having distinct kitchens, wells \& other Conveniences, and a Common Open Stone Staircase in the Center communicated with the several quarters ...My Appartments consisted of a small Antichamber, eating Room, Bed Chamber, Kitchen, \& two large Rooms in front, one which I made my Study or painting Room, \& the Other an exhibition—or Show Room.... ${ }^{20}$

This written description was accompanied by a sketch of the layout of his apartment, almost certainly drawn from memory and the only one of its kind in the "Memoirs" (Figure 1). Despite the fluidity of kitchen space in the early modern period and a corresponding neglect (as Sara Pennell has pointed out) of the kitchen in architectural histories, Thomas Jones' kitchen is clearly delineated in the layout of his house and even includes the position of two circular burners (fornelli).$^{21}$ However, visitors to Jones' apartment—friends and potential clients-were unlikely to have seen the kitchen. They would have come up the staircase and turned left into the antechamber and towards the public rooms at the front of the apartment. From the same antechamber, Jones, his wife, and their servants would have gone straight ahead by the "eating room" through to the back of the apartment to the kitchen. It is not clear from the sketch whether the kitchen looked out to a courtyard, but the mention of a well suggests that the apartment had access to an outdoor space, which was essential to the running of any kitchen in this period, even if Jones did not depict or describe it. ${ }^{22}$

20 "Memoirs," 95-96; the description and sketch appear at the bottom of facing pages in the manuscript (ff. 178-179).

21 Pennell, The Birth of the English Kitchen, 37-45.

22 On the use and transformation of space in Neapolitan palaces transformed into apartments for rental, including courtyards, see Maria Raffaela Pessolano, "Palazzi ad appartamenti a Napoli: Costruzioni, ricostruzioni, adequamenti," in L'uso dello spazio privato nell'età dell'illuminismo, ed. Giorgio Simoncini (2 volumes) (Florence, 1995), II, 429-453. My thanks to Diego Carnevale for this reference. 


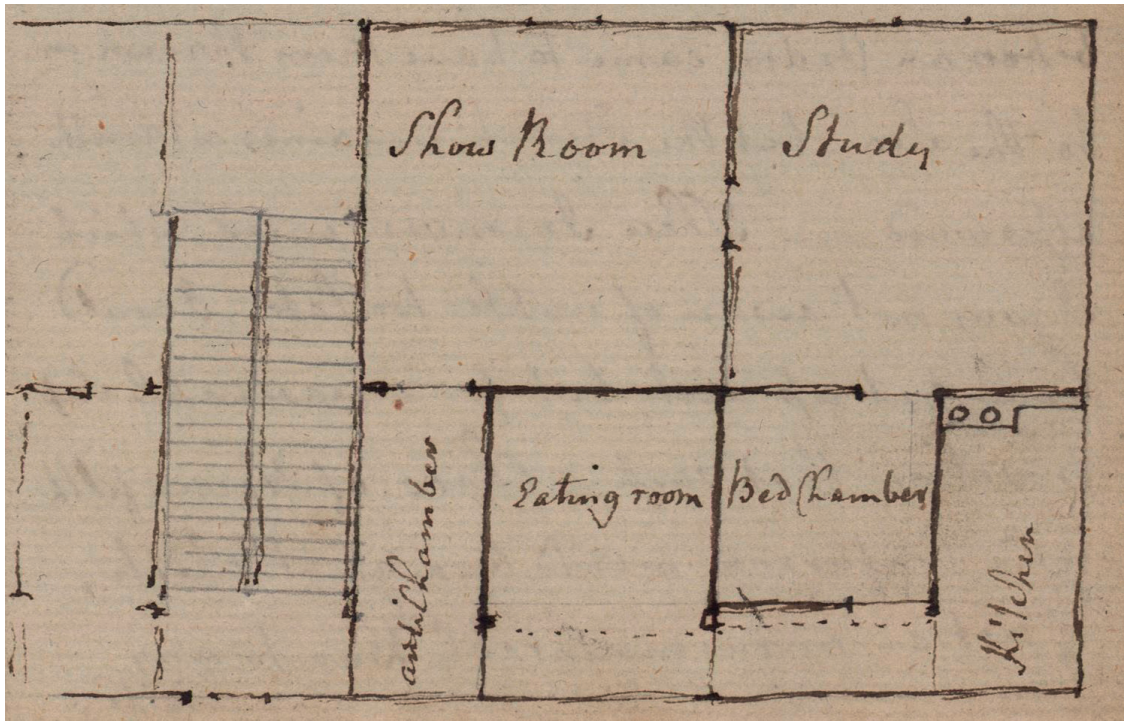

FIGURE 1 “Thomas Jones' Neapolitan kitchen," in "Memoirs of Thomas Jones, Pencerrig." NATIONAL LIBRARY OF WALES, MS 23812D, F. 179.

As Tara Hamling and Catherine Richardson have shown in the case of early modern England, the "backside" of a house provided essential space to service the kitchen away from the hearth or cooking facilities; food would often be prepared in an open space away from the kitchen or sometimes in a separate building. ${ }^{23}$ When Thomas and Maria were still living in Rome, on Via Gregoriana, near the Trinità dei Monti, they rented a ground floor room to keep chickens and store wood in what he describes as a rimessa (which Jones translates as a "Coach house" but which could also be translated as an outbuilding or shed). ${ }^{24}$ The courtyard in this busy and dense part of Naples must have served a similar function. Jones' accounts indicate that the family bought a goat several months after moving to Naples and that, initially, they were paying for vine fronds to feed it. ${ }^{25}$ It is a reminder that animals lived side-by-side with humans in this

23 Tara Hamling and Catherine Richardson, A Day at Home in Early Modern England: Material Culture and Domestic Life, 1500-1700 (New Haven, 2017), 67-71.

24 September 1779, "Memoirs," 9o; f. 160.

25 Jones paid 30 grani for a goat on 23 July 1780 and bought fronde di vigna per la capra for one grano over the next seven days; "Italian Account Book," f. $7 \mathrm{v}$ to f. 8r. He also bought Biada per la Capra on 27 July 1780 (f. 8r). On 1 July 1782, Jones records the buying of four live chickens (4 pollastrini vivi) when he was living in his second Neapolitan home in the hills near Capodimonte and likely to have had more outdoor space than by the port (f. $72 v)$. 
dense urban environment and supplied households with fresh milk to drink or possibly to make other fresh dairy products such as cheese and butter. ${ }^{26}$ Messier activities such as cheese-making or preserving which required water and sometimes specialized equipment meant that the kitchen necessarily extended outwards into these "backside" or open spaces.

While Jones' sketch of his apartment does not indicate the existence of such a space, his description does mention "wells and other conveniences" which would have been reached from the second floor by the main stone staircase and used for such activities. ${ }^{27}$ Jones bought carafes of vinegar as well as salt and sugar at very regular intervals - all products which could be used for preserving vegetables and fruit, even fish and meat, in an urban context. Jones records the buying of four ceramic vessels (4 vasi di terracotta) at the height of the summer of 1781 but there is no way of knowing whether these were jars to preserve pickles or store fruit compotes or even that they were simply drinking vessels. ${ }^{28}$ We know that Jones bought (once) some pickled cucumbers (Cidrioli sott'aceto) during his time in the apartment near the Dogana del Sale; however, it was only when he was living, from June 1782, in the hills near Capodimonte where almost certainly he had more space, that he paid for larger quantities of vinegar. ${ }^{29}$ Storage space, like outdoor space, must have also been at a premium in the città bassa, one of the most densely populated neighborhoods in one of the most densely populated cities in eighteenth-century Europe..$^{30}$ One wonders whether there would have been much room to store preserved food. Early modern households could not keep fresh food for long without refrigeration and most contemporary cookbooks contained recipes for preserving,

26 On this relationship in eighteenth-century London, see Thomas Almeroth-Williams, City of Beasts: How Animals Shaped Georgian London (Manchester, 2019).

27 Jones bought " 2 Buckets for the Well" for 13 grani a couple of days before he moved into the new apartment; "Italian Account Book," 26 May 1780, f. 2v, and fune per il pozzo (rope for the well) in early June for 60 grani; 3 June 1780 , f. $3 \mathrm{v}$.

28 "Italian Account Book," 31 August 1781, f. $27 \mathrm{v}$.

29 For pickled cucumbers, see his entry on 11 October 1780; "Italian Account Book," f. 11v. When he recorded the price of vinegar, he regularly paid 1 grano for vinegar during his time at the apartment near the Dogana del Sale and only once recorded paying 3 grani; 20 September 1781 , f. $28 \mathrm{v}$. Jones and his family moved to this new house in the hills with a view of the city after staying two years in the citta bassa; "Memoirs," 8 June 1782, 112; ff. 232234. There were larger payments for vinegar after his move in June 1782, for example, 3 grani for a carafa of vinegar; 1 September 1782 , f. $45 \mathrm{v}$. For a contemporary recipe for pickled cucumbers "che si conservano tutto l'anno, e se ne fa uso per insalatine, e per condimento di carni, e pesci lessi," see Vincenzo Corrado, Del cibo pitagorico, ovvero erbaceo, per uso de' nobili, e de' letterati (Naples, 1781), 32.

30 On the città bassa near the port, see Teresa Colletta, Città Portuale e Mercantile. La città bassa, il Porto e il mercato dall'VIII al XVII secolo (Rome, 2006). 
conserving, and pickling to address this problem. ${ }^{31}$ The urban environment therefore determined the kinds of products which Jones and his family were likely to buy - as we will see, mostly fresh food which could be bought and consumed on the same day — and it limited their capacity to preserve and store food as well.

It is more likely that some of the vinegar which Jones bought was used to dress his salad; he bought insalata and lettuga, which was available all year around in Naples, several times a week. ${ }^{32}$ In fact, he often bought salad and vinegar together and recorded it under one entry. ${ }^{33}$ The practice of lettuceeating was first made fashionable amongst British elites by late seventeenthcentury writers who sometimes advocated vegetarian diets-for religious or health reasons or in the interests of animal welfare. ${ }^{34}$ Vegetarianism has a long pedigree, and, in the eighteenth century, the emphasis was on its ancient origins as much as its health benefits. ${ }^{35}$ Vincenzo Corrado (1736-1836), the most popular cookery book author of late eighteenth-century Naples, published a cookbook devoted to vegetables, entitled, Del Cibo Pitagorico (Of Pythagorean Food), in 1781 when Jones was already resident in the city. ${ }^{36}$ Although Corrado makes no mention of it, Neapolitans had been known since the late Middle Ages as mangiafoglie - literally, leaf-eaters — until their diet of vegetables was supposed to have been replaced by a new reliance on pasta to become the mangiamaccheroni-or macaroni-eaters — by the eighteenth century. ${ }^{37}$ It is

31 Pennell, The English Kitchen, 79-81.

32 Jones bought insalata and lattuga all year round, from January to December, for example, more than twice a week in September 1781; "Italian Account Book," ff. 28r to 29r. He seemed to have acquired a taste for the more bitter cicoria in his last year in Naples, although it is possible that he cooked this as he often bought it with sausages or meat; 23 November 1782, f. 49r, or cauliflower or broccoli; 5 February 1783, f. 52v.

33 One grano for insalata aceto on 15 November 1780 and two grani for aceto insalata on 23 April 1781; "Italian Account Book," f.13r and f. 21r.

34 See, for example, Thomas Tryon, The way to health, long life, and happiness, or A discourse of temperance and the particular nature of all things requisite for the life of man to which is added, a treatise of most sorts of English herbs (London, 1683).

35 On the different iterations of vegetarianism in the eighteenth century, see EricaJ. Mannucci, "Settecento frugale: Intorno al vegetarianismo di Benjamin Franklin," in Studi storici dedicati a Orizio Cancila, eds. Antonino Giuffrida, Fabrizio D'Avenia, and Daniele Palermo (3 volumes) (Palermo, 2011), III, 1147-1165.

36 The book was dedicated to a British resident in Naples, John Child, and Earl Tylney, who died there in 1784. Corrado was also author of Il Cuoco Galante (1st ed. 1778), discussed below, and Il Credenziere del Buon Gusto (1789).

37 This shift in representation was studied by Emilio Sereni, a historian of Italian agriculture, in three articles from the 1950s, republished as Note di storia dell'alimentazione nel Mezzogiorno: Inapoletani da "mangiafoglia" a "mangiamaccheroni" (Gattatico (RE), 2013). 
not clear whether this shift in representation corresponds to an actual shift in consumption patterns. However, the variety of vegetables (including lots of leafy vegetables) available in the shops, markets, and streets of the city is evident in Jones' account book. Along with the salad ingredients such as radishes and erbette, Jones also recorded the purchase of two kinds of cabbage (colli and capuccio), broccoli, cauliflower, celery (selleri), radishes (rafanelli), leeks, peas, broad beans, artichokes, tomatoes, mustard greens (senape), beetroot (bietola), Swiss chard (bieta), borage (boraci), spinach, turnips (rape), fennel, onions, and cucumbers, all of which appear in Corrado's cookery book. Jones was able to buy fresh vegetables every day of the week in Naples and he clearly delighted in their freshness, noting the first peas of the spring in April 1782, with the words "for the first time" (per la prima volta) in his accounts. ${ }^{38}$ As we shall see, this variety was made possible by a highly complex and sophisticated network of fresh food provisioning in the city. For Jones, eating vegetables was a sign of his alimentary acculturation rather than any indication of his following of food fashions; however, it was also determined by the urban context in which he lived. Dried legumes such as chickpeas and lentils were certainly sold by general grocers in Naples but neither of them appeared in Jones' account. ${ }^{39}$ He regularly recorded the purchase of broad beans (fave) which were available both fresh and dried in Naples, but the fact that he bought them only from very late March to early June suggests that he only ever ate fresh broad beans. ${ }^{40}$ There might have been no space for storing dried goods in Jones' kitchen but there was also no need.

Urban life determined other kinds of alimentary practices which had an impact on the urban kitchen. Renata Ago suggests that inhabitants of early modern Rome did not have much room for preparing food and cooking meals-many Romans had no hearths and they also had limited cooking equipment. This hypothesis, however, has not been tested beyond the evidence gathered from

38 Jones bought 3 mazzi or bunches of piselli which confirms that he was buying fresh not dry peas which would have been measured by weight rather than by the bunch; "Italian Account Book," 29 April 1782, f. 39r.

39 The licence for "Bottegaro Pizzacarolo" (the equivalent of a grocer) includes the right to sell dried and rehydrated legumes along with other dried goods such as soap, salt, and flour in the Archivio Storico Municipale di Napoli (hereafter cited as ASMuN); ASMuN, Prima serie (1387-1805), Tribunale degli Eletti o di S.Lorenzo, Real Portolano, (1780-1806), Licenze e Matricole 1780-1806, Fasc. 26, Volumetto n. 2, f. 44v.

40 He writes: Fave/pr la prima Volta 2 Rotole; "Italian Account Book," 2 April 1782, f. 38r. In comparison, monasteries and convents which had the storage space record the purchase of large quantities of legumes. Romano based his table of prices for legumes from these records, confirming that favette were dried broad beans (fave sgusciate). See the Table "Prezzi dei legumi," in Romano, Prezzi, salari, e servizi a Napoli, 73-75. 
inventories, despite the fact that we know that there were many objects as well as fixed fittings which were not seen or included by notaries. ${ }^{41}$ For instance, we know that, by the mid-eighteenth century in Rome, floor plans for smaller and more modest apartments which were built as rental properties included spaces for kitchens. ${ }^{42}$ Jones' accounts for Naples provide alternative and rich evidence to study further the workings of the urban kitchen. In 1779, while still in Rome, Jones and his friend and artist William Pars decided to cook for themselves. He wrote in his "Memoirs":

we were both heartily sick of the Italian Soups and Stews, determined to live as much as possibly we could, in the English Stile-On this Occasion we were obliged to be our own Cooks \& consequently spent much of that time in the Kitchen which might have been perhaps more profitably spent in Our Studies, to the great Amusement of those Wags among our friends, who notwithstanding their many Strokes of Pleasantry on the Subject, were very glad to sit down to a piece of Roast Beef and Plumb pudding- 43

Jones does not comment on how he and Pars engineered the roasting of meat in his Roman apartment, but it is very unlikely that Jones had an open hearth in the kitchen of his second-floor apartment in Naples. The two fornelli depicted in his sketch probably represent two burners on top of a marble or stone counter, a kind of in-built stove into which fuel could be added underneath. The burners would have consisted of holes onto which an iron grid or plate was laid to conduct heat and onto which a tripod or trivet and then ceramic pots would then have been placed. ${ }^{44}$ This kind of kitchen range in an urban environment represented a move away from wood to charcoal as the main source of heat and also encouraged slower cooking and the use of different kinds of kitchen equipment. ${ }^{45}$ This set-up necessarily determined the kinds of recipes which could be attempted.

41 Giorgio Riello, "Things Seen and Unseen: The material culture of early modern inventories and their representations of domestic interiors," in Early Modern Things: Objects and their Histories, 1500-180o ed. Paula Findlen (London, 2013), 125-150.

Giovanna Curcio, "Abitare a Roman nel settecento: La casa 'moderna," in L'uso dello spazio privato nell'età dell'illuminismo, ed. Giorgio Simoncini (2 volumes) (Florence, 1995), II, 359, Fig. 122.

436 February 1779, "Memoirs," 87; ff. 148-150.

44 My thanks to Diego Carnevale, Alida Clemente, and Brigitte Marin for this suggestion.

45 For England, Pennell, Birth of the English Kitchen, 61-64 and 72-74. 
Vincenzo Corrado included recipes both for roasting as well as stewing in his cookery book, Il Cuoco Galante (The gallant cook), first published in Naples in 1778 , with a third edition in 1786 . The variety and abundance of his seasonal menus and the elaborate table settings which appear at the end of the book suggest that he was targeting wealthier households. ${ }^{46}$ These households would have had the space and economic capacity to keep a large fire going. However, Jones, like many Neapolitans with smaller urban kitchens, was limited to the cooking of soups and stews which he had so despised in Rome. Jones' accounts provide evidence of this more moderate cooking regime. On the same day that he signed his lease for the new apartment, May 26, 1780, Jones bought two tripods (or trivets) and a gridiron along with all that was needed to build a bed (boards, irons, ticking, straw) ${ }^{47}$ Several days later, on June 1, he recorded the purchase of a bastardella col coperchio, a round-bottomed pot with two handles and a lid, made from copper and specifically designed for cooking meat. ${ }^{48}$ The cost of Jones' metal pot with a lid suggests that it might have been second-hand, since 4 grani was close to the cost of a ceramic pot called a tegame many of which he also bought and presumably broke and replaced over his time in Naples. ${ }^{49}$ The naming of cooking pots, their function and even the material of which they were made are notoriously difficult to match up in the history of kitchenware. Archaeological evidence from eighteenth-century Barcelona shows the variety of kitchenware in an urban context but also the difficulty in determining their specific functions in relation to textual sources. ${ }^{50}$

46 Vincenzo Corrado, Il Cuoco Galante (3rd edition, Naples, 1786), 197-230. For a reproduction of one of the table settings, see Treasured Possessions from the Renaissance to the Enlightenment, eds. Victoria Avery, Melissa Calaresu, and Mary Laven (London, 2015), Fig. 224, 204.

47 "Italian Account Book," 26 May 1780, f. 2v. On the day that he moved in, he bought a tinder box and fire shovel and the next day he paid for the delivery of 25 rotoli (just over 50 pounds) of charcoal. Between the entries for 29 and 30 May 1780, Jones writes, in a different ink, "Lay for the first night at my new Lodgings" (f. 3r).

48 "Italian Account Book," 1 June 1780, f. 3v. The definition is "Vaso di rame stagnato chiuso, per cuocervi entro carne." Vocabolario degli Accademici della Crusca, (4th edition, Florence, 1729-1738), Vol. 1, 394.

49 Jones bought two tegami on 22 July 1780 for 7 grani ("Italian Account Book," f. $7 \mathrm{v}$ ), and one for five grani on 24 November 1781 (f. $32 \mathrm{r}$ ). In comparison, the cost of the metal gridiron and two tripods was 26 grani ( 26 May 1780, f. 2v). On ceramic durability and consumer choice in early modern England, see Sara Pennell, "For a crack and a flaw despis'd': thinking about ceramic semi-durability and the 'everyday' in early modern England," in Everyday Objects: Medieval and Early Modern Material Culture and its Meanings, eds. Tara Hamling and Catherine Richardson (Abingdon, 2010), 27-40.

$5^{0}$ Julia Beltrán de Heredia Bercero, "Les llars barcelonines a través de l'arqueologia," in Interiors domestics. Barcelona 1700 (Barcelona, 2012), 243-281. 
While Corrado makes no distinction between different kinds of cooking pots, using the term casserola throughout Il Cuoco Galante, he indicates, in a later publication, the production and circulation of ceramic kitchenware known as tegami from Sessa, a city on the Via Appia north of Caserta. ${ }^{51}$ It is likely that the bastardella and the tegami were used for the kinds of stewing and soupmaking which was possible in Jones' kitchen. The pots could have been placed on top of the tripods on the fornelli or on the gridiron which was laid across the holes in the kitchen range. A single page in Jones' account book is dedicated to recipes for food-all of them beef or mutton stews using a tegame or, in his words, "Stewpan." He writes, "To dress Beef or Mutton alla Genoese," "do it over a slow fire ... the Pan must be covered and care taken that the meat does not burn." ${ }^{2}$ It is clear, therefore, that the kinds of cooking equipment bought by Jones were used to cook on a slower and contained fire on top of the fornelli, rather than on an open hearth.

In this way, Jones' food choices were determined by the material limits of his urban environment. It is possible that the amount and variety of offal consumed by Jones and his family had to do with the suitability of this kind of meat by-product to slower cooking methods such as stewing. Jones bought mutton or castrato two or three times a week-in a variety of different cuts but also as different forms of offal (head, liver, tongue, feet, sweetbreads) —all of which would have been suitable for cooking in stews and soups, as Corrado's chapter on mutton attests. ${ }^{53}$ On a winter day in 1781 , Jones bought three ox tongues which were more expensive (100 grani or 1 ducato) than any other purchase that day, including other cuts of meat, suggesting that cost was not the sole determinant in his choice of offal. ${ }^{54}$ With no space or ventilation for an open hearth, Jones acquired kitchenware which was suitable for his urban kitchen and, in turn, he developed corresponding cooking practices which made best use of these material limits. The lack of storage space also meant that Jones was compelled to buy the wide variety of seasonal fruit and vegetables which was available in the city and consume them on the day. In this

$5^{1}$ On Sessa, now known as Sessa Aurunca, he writes: "ben stabilita la fabbbrica dei vasellami di creta per cucina, li quali, per chè ottimi, son ricercati, e se ne fa commercio, e da pertutto girano sotto il nome di pignatte, e tegami di Sessa" (Vincenzo Corrado, Il notiziario delle produzioni particolari del Regno di Napoli (Naples, 1792), 40-41). "Italian Account Book," f. $76 \mathrm{v}$. A recipe for veal alla Genovese includes similar instructions in Corrado, Cuoco Galante, 14.

53 Corrado, Cuoco Galante, 28-30. Jones often indicated the different cuts and forms of meat, for example, on one page of his accounts, from 14 to 22 October 1780, he bought Spaletto di castrato, Testa di Castrato, and Castrato. "Italian Account Book," f. 12 .

"Italian Account Book," 2 February 1781, f. 17r. 
way, urban life determined alimentary practices which had an impact on the kitchen. However, the question remains to what extent these conditions were specific to the city of Naples.

\section{The Neapolitan Kitchen}

"Campania Felix," the name which the ancient Romans gave to the land around Naples, recognized the fertility of the area and its soil. It was a trope which did not disappoint eighteenth-century visitors who were astonished by the vegetation as they approached the city; the variety of fruit and vegetables on sale atwhat seemed - all seasons of the year confirmed the truth behind the trope. In 1700, John Jackson, in a letter to his uncle, Samuel Pepys, was surprised to be able to buy "sparagrass, green pees, and melons, at no unreasonable rates" in early March. ${ }^{55}$ The astonishment of northern Europeans visiting the city, however, is matched by the archival evidence behind the provisioning of one of the largest cities in Europe. While Jones' meticulous accounts reveal clearly the abundance of the countryside around the city, records from the municipal archives in Naples record the complexity and variety of making that food available on the streets and in its shops.

No urban history of food can be complete without some understanding of a city's hinterland, for the foodways which converged in Jones' kitchen from the streets of Naples extended to the orchards, gardens, and farms (masserie) outside of the city walls and from the hills above and along the coast. Vincenzo Corrado's seventh publication, Il notiziario delle produzioni particolari del Regno di Napoli (Bulletin of special products from the Kingdom of Naples) of 1792 recognized the importance of those links, by describing the particular products of towns and cities outside of the capital. It was part of a patriotic project and typical of this period in Naples - the book was dedicated to the city (Alla nobilissima Partenope) — in which he recognized the natural abundance of the Kingdom but more importantly celebrated the skillful use of agriculture and animal husbandry for its commercial advantage..$^{56}$ Not surprisingly, Corrado's primary interest was food production: there were maccheroni and other paste fine from Torre dell'Annunziata, large and tasty cherries from Marano, turkeys (tacchini, ossiendo gallinacci) from Caivano, snow from Vico

55 Letter from John Jackson to Samuel Pepys, 9 March 1700, in Private Correspondence and Miscellaneous Papers of Samuel Pepys, 1679-1703, ed. J.R. Tanner (2 volumes) (London, 1926), I, 293.

$56 \quad$ Notiziario, 1-4, 18-22. 
Equense "for the use and commodity of the City of Naples," veal and dairy products such as ricotta and fior di latte from Sorrento, asparagus, quails and songbirds (beccafichi) from Massa, and peas, artichokes, various greens, figs and other fruits from Pozzuoli. ${ }^{57}$

Food in the city of Naples was then marked by the distances travelledvegetables on the backs of mules, snow in the hulls of boats, figs pushed in carts through the city gates. Many of these goods from the hinterland found their way into Jones' kitchen in the città bassa. For instance, he often bought fish in the evening - after the boats had landed and the fish had made their way from the wholesale market to the fishmongers - and indicated this in his accounts with a note of alla sera (in the evening) or alla notte (at night). ${ }^{58}$ By 1781, he had gained enough local knowledge while resident in the city to know what were understood by Neapolitans as the superior qualities of veal coming from Sorrento, making this distinction in his accounts. ${ }^{59} \mathrm{In}$ fact, he had been to Sorrento a year earlier and noted in his "Memoirs": "This District has been celebrated for the richness of its Milk ever since the days of Galen-The Veal and Butter are still articles of Luxury in Naples." ${ }^{\prime 60} \mathrm{He}$ seemed less concerned to distinguish the varieties of fresh cheeses from near Sorrento-recording simply "cheese" (formaggio) in his account - and, if anything, he showed a preference for English and Dutch cheese ${ }^{61}$ Not everything came from outside of the city, for we know that enterprising citizens, often women, across Europe had their own equipment to make food products in their homes and then sell them, often outside of municipal regulations. ${ }^{62}$ On a Wednesday in January 1781 Jones recorded: "Last Monday paid to Madama Tommasi for one and half rotoli of butiro" (a kind of unsalted butter which appears frequently in his accounts and in contemporary Neapolitan recipes). It is the only time in his accounts

57 Notiziario, respectively, 30, 33, 35, 53, 54-5, 56, and 58. For recipes for beccafichi and another kind of songbird, ortolani "which need to be eaten as soon as possible after killing them," see Corrado, Cuoco Galante, 68-70.

$5^{8}$ For example, "Italian Account Book," 18 January 1781, f. 16v. On the fish market in Naples, see Alida Clemente, Il mestiere dell'incertezza: La pesca nel golfo di Napoli tra XVIII e XX secolo (Naples, 2009).

59 For example, "Italian Account Book," 11 October 1781, f. 26v.

$60 \quad 25$ October 1780, "Memoirs," 99; f. 190.

61 For example, "Formaggio d'Olanda," in "Italian Account Book," 27 June 1780, f. 6r.

62 Danielle van den Heuvel, "Guilds, Gender Policies, and Economic Opportunities for Women in Early Modern Dutch Towns," in Female Agency in the Urban Economy, 1640-1830, eds. Deborah Simonton and Anne Montenach (New York, 2013), 116-133, and Tessa Storey, "Face Waters, Oils, Love Magic and Poison: Making and Selling Secrets in Early Modern Rome," in Secrets and Knowledge in Medicine and Science, 1500-1800, eds. Elaine Leong and Alisha Rankin (Farnham, 2011), 158-160. 
that he mentions a seller's name, suggesting perhaps that he had made this "one-off" purchase from an enterprising neighbor close-by for a late dinner of seabass, butter, and herbs which he had also bought that evening. ${ }^{63}$ Buttiro might have been precisely the kind of product made in one of the "backsides" of a kitchen or in a Neapolitan courtyard.

This city of Naples is also vividly present in Jones' kitchen. He occasionally uses Neapolitan words for specific fruits and vegetables, often providing his own translations in brackets in English or Italian-for example, carrots appear as pistonaccia or pastinacchi and cherries as cerase. ${ }^{64} \mathrm{He}$ also refers regularly to the purchase of alici which, as Corrado points out, is what Neapolitans call fresh anchovies (rather than acciughe in the rest of the Italian peninsula, a term that Jones never uses). ${ }^{65}$ There are also words difficult to decipher in his accounts and one wonders whether the unusual spelling simply evokes his hearing of a word in Neapolitan or Italian. For example, he cites the purchase of pedrocelli or pedroncelli which might be a misinterpretation of the Neapolitan word for parsley, petrosino. ${ }^{66}$ In other entries, he specifies the buying of baked or fried goods particular to southern Italy such as taralli; in one instance, Jones adds the word schiambelli in brackets which must correspond to ciambelle, his approximation of the word that he heard on the street. ${ }^{67}$ His accounts therefore do suggest the extent of his family's food acculturation over the three years in Naples.

Jones also bought "maccaroni" (as he spelled it) in the summer of his first year in Naples, in July 1780, after which it was a regular item in his accounts

63 "Italian Account Book," 10 January 1781, f. 16r. This is the only time that he indicates from whom he bought the buttiro, suggesting that it was an unusual purchase. For a recipe, using those ingredients, see "Spigola all'Acetosa," in Corrado, Cuoco Galante, 78.

64 For pistonaccia, Jones provides a translation in Italian (carrotte); "Italian Account Book," 9 February 1782, f. 36 r. Corrado dedicates a chapter of his vegetarian cookbook to Pastinache in which he explains that there are two kinds, rosse and gialle; Corrado, Cibo Pitagorico, 29. Jones indicates earlier that he bought carrotte gialle; 23 November 1780, f. 13v. See also Raffaele d'Ambra, Vocabolario Napolitano-Toscano Domestico di Arti e Mestieri (Naples, 1873), 463 and 466.

65 Corrado, Cuoco Galante, 83.

66 He often bought it together with onions, such as on 14 February 1781; "Italian Account Book," f. 17v. Variations of petrosino include petrosello, in d'Ambra, Vocabolario NapolitanoToscano, 287 and 512. My thanks again to Adam Ledgeway for this suggestion.

67 "Italian Account Book," 17 December 1782, f. 5or. The word ciambella appears as a Neapolitan equivalent of tarallo, in d'Ambra, Vocabolario Napolitano-Toscano, 372. According to Adam Ledgeway, he might have been "trying to imitate the voiceless fricative pronunciation (viz. the 'sh' sound) of intervocalic 'c' before 'I' and 'e', hence mixes in part the English spelling of 'sh' with Italian 'sc[h]I' > 'schi'.' Personal communication, 8 September 2019 . 
until his departure from Naples in August 1783, when he arranged for the delivery of twenty-four pounds of it, along with five pounds of cheese (cascio bianco $p^{r}$ i maccaroni) to the ship which would take Jones and his family back to England. ${ }^{68}$ It is worth noting that Corrado makes no mention of macaroni in any of his cookbooks, suggesting that it was not favored by his aristocratic readers and was eaten instead by the wider Neapolitan populace, as represented in contemporary stereotypes. ${ }^{69}$ Jones' family's consumption of pasta might correspond to the shift recognized by contemporaries and later food historians, as Neapolitans moved from a leaf-based diet to one dependent on dried pasta, to become mangiamaccheroni. ${ }^{70}$ For British contemporaries, of course, this kind of food acculturation brought moral anxieties as suggested by the suspicious and effeminate figure of the well-travelled macaroni in satirical prints in this period. ${ }^{71}$

Judging by the amounts paid for in dry measures of macaroni in his accounts, Jones was unlikely to have bought it as a ready-cooked dish. He did, however, buy a variety of prepared food and services available on the street, a variety which is richly represented in contemporary images and in the archival sources. ${ }^{72}$ The richness of what was on offer in Naples is indicated by licenses issued to shops and street vendors and corresponds to some of Jones' seasonal purchases-snow for wine in the summer, roasted artichokes in the spring, and cooked apples in the winter. ${ }^{73}$ Not surprisingly, considering the limits of urban kitchens such as Jones', a range of cooked and prepared food was available on the streets and the city's taverns - cooked legumes, boiled eggs, and fried pizze and pastries stuffed with meat, vegetables, and fish. ${ }^{74}$ Municipal authorities ensured that shops and their itinerant vendors were able to meet the food needs of this densely populated city by granting licenses which allowed

6812 and $23 / 4$ rotoli, respectively, on 1 and 4 August 1783; "Italian Account Book," ff. 6or-v. Jones always spelled it as maccaroni in his accounts. See also "Memoirs," 3 August 1783, 126; f. 378 .

69 M. Calaresu, "From the Street to Stereotype: Urban Space, Travel and the Picturesque in Late Eighteenth-Century Naples," Italian Studies, 62/2 (2007): 189-203.

$70 \quad$ See fn. 37 above.

71 Peter McNeil, Macaroni Men and the Eighteenth-Century Fashion World (New Haven, 2018).

72 Jones indicated directly once that he had paid a street vendor, giving 20 grani to a venditore di piazza; "Italian Account Book," 2 April 1783, f. 55r.

73 "Italian Account Book," 12 December 1781, f. 33r; 12 April 1781, f. 2ov; 13 July 1780, f. 7r.

74 ASMuN, Prima serie (1387-1805), Tribunale degli Eletti o di S. Lorenzo, Real Portolano, (1780-1806), Licenze e Matricole 1780-18o6, Fasc. 26, Volumetto n. 2, f. 37r ("Venditore di legumi scaldati"), f. 40v ("L'arte de pollieri per la vendita delle ova cotte"), f. $26 \mathrm{r}$ ("Licenza grande di Frittore"). 
them to sell their food across the city. ${ }^{75}$ In this way, Jones' Neapolitan kitchen was necessarily connected to what was available on the street and in the shops-not only the wealth and variety of fresh produce coming by boat and sea into the city but also the food prepared in the backrooms of the city and on the street through a complex and highly regulated system of provisioning.

While the city's environs had been celebrated for its natural fertility, the size of the population required careful management of foodways in and through the city. Jones' accounts of his daily purchases reflect this movement, temporally across the day — coffee in the morning and fresh fish at night—and seasonally across the year-peas in early spring and strawberries through the summer - and spatially across the city - from the courtyard of his apartment to the city's street corners - and its hinterlands, and back to the Neapolitan kitchen that he began painting in the light of a May day in 1781 .

\section{Conclusion}

The specificity and comprehensiveness of Thomas Jones' "Italian Account Book" are beguiling, and we could reconstruct in detail his first Neapolitan kitchen from scratch and his household consumption in its entirety over three years from his arrival in May 1780 until August 1783. Jones' detailed accounts, studied alongside his memoirs, could act as a kind of contained time capsule for writing his biography. As Craig Cessford has suggested, single archaeological deposits from the eighteenth century, when studied alongside archival material, offer the tempting possibility of "an archaeology of individuality," even if, in the end, they necessarily materialize different temporalities over a life and over generations. ${ }^{76}$ In those first days in Naples, Jones bought a salt-cellar, the most portable of culinary equipment and, one could argue, the most symbolic of a family's culinary life, suggesting an entirely new start. ${ }^{77}$ However, the nature of the sources means that we do not know whether the lidded bastardella

75 The licence for a Frittore gave the right to sell pizzette "from their shop, and stall, as well as sending them out with their boys (garzoni) in Naples and the villages"; "Licenza grande di Frittore," f. 26r, cited from ASMuN, in the footnote above.

76 Craig Cessford, "Assemblage Biography and the Life Course: An Archaeologically Materialized Temporality of Richard and Sarah Hopkins," International Journal of Historical Archaeology 18 (2014): 555-590. See also the individual family studies reconstructed from the Born archaeological site in Barcelona with contemporary inventories, in Albert Garcia Espuche, La Ciutat del Born: Economia i vida quotidiana a Barcelona (Segles XIV a XVIII) (Barcelona, 2009), 167-381.

"Italian Account Book," 29 May 1780, f. 3. 
was their first cooking pot or whether Jones and his common-law wife, Maria, had also brought other pots and pans from their apartment in Rome. Kitchens are also animated by labor. This might have been Thomas Jones' kitchen, but it is unlikely that Jones fetched the water from the well, preserved the cucumbers, and stirred the beef stew. Almost certainly, it was the women described as receiving monthly payments (mesata) in the accounts—-first, to the servant (alla serva) and later (and mostly) to Caterina and occasionally to Angellela and Mariuccia (their written names invoking a Neapolitan intonation). ${ }^{78}$

It would be tempting to use these household accounts simply in order to fill in our knowledge of the biography of Thomas Jones. Instead, what I have sought to do here is to look beyond the individual and offer a material culture analysis of Jones' accounts, providing an integrated and sensitive reconstruction of a space over time, through which night and day, sounds of the street, and the traces and seasons of food ways emerge. In this way, Thomas Jones' kitchen becomes animated - not by the survival of his painting or specific objects - but by a contextualized analysis of his accounts within his urban environment. This is as much a material cultural analysis of the city of Naples in the 1780 s as an exercise in food history. It also re-evaluates the extent of the acculturation of British residents in Italy such as Thomas Jones, which may bring us closer to a more nuanced understanding of the urban experience of Grand Tourists. In this way, it brings to life the city in which Jones and his family lived, loved, cooked, and ate.

\section{Acknowledgements}

Versions of this article were presented in Cambridge, Canterbury, London, and Tours, and I am grateful for the questions and queries from audience members as well as for suggestions, clarifications, and revisions from Tommaso Astarita, Diego Carnevale, Alida Clemente, Irene Galandra, Mary Laven, Adam Ledgeway, Brigitte Marin, Joan Pau Rubiés, Alex Walsham, and the two anonymous readers for this journal.

78 "Italian Account Book," 22 July 178o, f. 7v, 10 August 1782, f. 44 v and 4 August 1783, f. 6ov. 